\title{
Investigation on Structural Analysis of Flat Head Piston
}

\author{
Cheekoti Venkata Rajam ${ }^{1}$, Dr. Geetanjali V Patil ${ }^{2}$, Dr. M.I.Sakri ${ }^{3}$, Dr.P.V.K.Murthy ${ }^{4}$ \\ ${ }^{1}$ Research Scholar in Mechanical Engineering, BLDEA's V.P. Dr. P.G. Halakatti College of Engineering and \\ Technology, Vijayapur-586103, Karnataka, India. \\ ${ }^{2}$ Professor, Department of Mechanical Engineering, BLDEA's V.P. Dr. P.G. Halakatti College of Engineering and \\ Technology, Vijayapur-586103, Karnataka, India. \\ ${ }^{3}$ Professor, Department of Mechanical Engineering, BLDEA's V.P. Dr. P.G. Halakatti College of Engineering and \\ Technology, Vijayapur-586103, Karnataka, India. \\ ${ }^{4}$ Principal, Annamacharya Institute of Technology and Sciences, Hyderabad, Telangana, India.
}

Received Date : October 07, 2021 Accepted Date : October 27, 2021 Published Date : November 07, 2021

\begin{abstract}
In the investigation on structural analysis of flat head piston deflection and stress equations plays major role in mathematical modeling. The same has been used in this analysis. In the part of the analysis the thickness of the flat head of the piston is considered as the same of that of simply supported circular plate and the loads are applied on it reacts with the supports held at the top of the gudgeon hole. The piston is same as one side closed cylinder and ended with flat circular plate. It is the most general that the deflections due to axial loads are neglected. Hence the deflection and stress equations of the simply supported circular plate are adopted. Aluminum is taken as material of the component throughout the analysis and grey cast iron is taken as material for the rings in the modeling of the piston. Flexural rigidity plays a major role in the calculation for the analysis. The results of the mathematical analysis have been compared with the same of that of simulation using ANSYS software.
\end{abstract}

Key words: Flat Head Piston, Deflection, Stress, Structural Analysis

\section{INTRODUCTION}

A piston is an important and main component of an Internal Combustion(IC) engine moving in between top and bottom dead centers. Every IC engine is working on the combustion of liquid or gaseous fuel like diesel, bio-diesel, petrol or compressed natural gases etc [1]. Thermal expansion of gases during and after combustion of fuel takes place and as a results the forces exerts on the piston head causes deflection and stresses induces on it due to fatigue loading in the cyclic process. This takes place due to long time running of an engine[2],[3]

In view of design and modeling of the strengthened piston these deformations and stress induced are necessary to determine and can be done by the structural analysis. The crown or flat head of the piston can be considered as circular plate. The circular plate undergoes the deformation and stress induced due to loads applied on it. In the similar way the top of the flat head undergoes deformation and stress induces the stress due to thermal loads applied on it. In the cyclic process the fatigue loading takes place due to these thermal loads for long time running of the piston. In case of the piston the thermal loads are considered as the loads applying on the circular flat head which are normal to the surface.

The supports in case of the piston are fixed at gudgeon hole as its pin lift and reacts to the thermal loads applied on the top and similar to that of circular plate. The deflection due to axial loads are however negligible. Hence the supports can be held at any point of the distance from the head of the piston.

The analytical solution for the deformation and stress induced in the flat head of the piston can be obtained in the same way that of circular plate. The same has been analyzed using ANSYS software for the comparison of the results.

\section{MATERIALS}

Aluminum alloys can be selected as base metal for piston since it has good thermal conductivity [4]. The performance can be improved on heat treatment process [5]. Most generally the cast iron can be used as a metal for the piston rings [6].

The temperature will rise and fall on combustion of fuel takes place on the top and cooling of engine respectively. As a result of the thermal loads acts on the piston head, the structure of the piston will undergoes to deformation and stresses will be induced ${ }^{[7][8]}$. Hence the thermal properties are also important along with the physical properties. Therefore thermal properties will also be taken into consideration while modeling and design of the piston for structural analysis. The following Table I represents the maximum values of physical and thermal properties aluminum and cast iron for piston and piston rings respectively [9]-[13]. 
Table 1: Properties of Piston and its Coating Materials.

\begin{tabular}{|c|c|c|c|}
\hline \multicolumn{2}{|c|}{ Physical-Thermal Properties (in SI units) } & \multirow{2}{*}{$\begin{array}{l}\begin{array}{l}\text { Piston } \\
\text { Al Alloy }\end{array} \\
2685\end{array}$} & \multirow{2}{*}{$\begin{array}{l}\begin{array}{l}\text { Piston Rings } \\
\text { (CI) }\end{array} \\
7100\end{array}$} \\
\hline \multirow{5}{*}{ 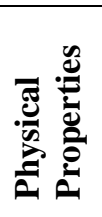 } & Density $\left(\mathrm{Kg} / \mathrm{m}^{3}\right)$ & & \\
\hline & Modulus of Elasticity (GPa) & 85 & 190 \\
\hline & Poisson's Ratio & 0.3 & 0.3 \\
\hline & Ultimate Tensile Strength(MPa) & 385 & 910 \\
\hline & Tensile Yield Strength (MPa) & 320 & 610 \\
\hline \multirow{3}{*}{ 焉 } & Thermal Conductivity $\left[\mathrm{W} / \mathrm{m}^{\circ} \mathrm{C}\right]$ & 172 & 15 \\
\hline & Thermal Expansion $\times 10^{-6}\left[1 /{ }^{\circ} \mathrm{C}\right]$ & 22 & 11 \\
\hline & Specific Heat $\left[\mathrm{J} / \mathrm{Kg}{ }^{\circ} \mathrm{C}\right]$ & 855 & 450 \\
\hline
\end{tabular}

\section{MODELING AND DESIGN OF THE PISTON}

Mathematical modeling is the part of the design and it is the description of calculations using various formulae for known and unknown parameters [14],[15]. The model and design of the piston can be developed by Finite Element Method and same can be done by using ANSYS Software.

\section{DIMENSIONS OF THE PISTON}

The following dimensions shown in the Table II are obtained from the calculations consisting of various respective formulae [16].

Table 2: Design Specifications

\begin{tabular}{|c|c|c|}
\hline S.No. & Dimensions & $\begin{array}{c}\text { Size in } \\
\text { mm }\end{array}$ \\
\hline 1 & Length of the Piston(L) & 90 \\
\hline 2 & Cylinder bore/outside diameter of the piston(D) & 80 \\
\hline 3 & Thickness of piston head $\left(\mathrm{t}_{\mathrm{h}}\right)$ & 12 \\
\hline 4 & Radial thickness of the ring $\left(\mathrm{t}_{1}\right)$ & 2 \\
\hline 5 & Axial thickness of the ring $\left(\mathrm{t}_{2}\right)$ & 2 \\
\hline 6 & Width of the top land $\left(\mathrm{b}_{1}\right)$ & 12 \\
\hline 7 & Width of other ring lands $\left(\mathrm{b}_{2}\right)$ & 4 \\
\hline
\end{tabular}

\section{STRUCTURAL ANALYSIS OF THE PISTON DETERMINATION OF DEFLECTION AND STRESS}

The piston will undergo the deformation and stresses induced due to heavy loads applied on its flat head during the combustion. Hence in the structural analysis it is important to calculate using analytical method.

In this analysis circular plate theory is adopted as the head of the piston can be treated as a simply supported circular plate subjected to uniform distribution loads.

The deflection is given as

The supports are taken at the top point of the gudgeon hole and reacts to thermal loads. However the distance between the point of loads applied and the supports are not taken into consideration because the deflection due to axial loads are neglected. Hence the following equations can be used.

In circular plate with simply supported edges, the deflection of the surface due to pure bending by the moments is given by

$$
\omega=\frac{q\left(a^{2}-r^{2}\right)}{64 D}\left(\frac{5+\vartheta}{1+\vartheta}\left(a^{2}-r^{2}\right)\right)
$$

Where

$\mathrm{q}$ is Intensity of a continuously distributed load $\vartheta$ is Poisson's ratio

$\mathrm{a}$ is radius of the piston circular flat head

$r$ is distance from a centre to a particular point and

Flexural rigidity is given by

Where

$$
D=\frac{E t^{3}}{12\left(1-\vartheta^{2}\right)}
$$

E is Yung's Modulus of material $t_{h}$ is thickness of piston flat head 
Substituting $\mathrm{r}=0$ then the deflection of the piston head at the centre is maximum and is given as

$$
\omega_{\max }=\frac{(5+\vartheta) q a^{4}}{64(1+\vartheta) D}
$$

The Maximum bending moment occurs at the centre of the piston flat head and is given by

$$
M_{r}=M_{t}=\frac{3+\vartheta}{16} q a^{2}
$$

And the Maximum Stress is given by

$$
\left(\sigma_{r}\right)_{\max }=\left(\sigma_{t}\right)_{\max }=\frac{6 M_{r}}{2}=\frac{3(3+\vartheta) q a^{2}}{8^{2}}
$$

The above equations are obtained from the small deflection or classical plate theory.

\section{ASSUMPTIONS:}

According to Kirchhoff's hypotheses the following assumptions are made

1. The loads or pressure applied on the piston head are straight and normal to the surface
2. The deflection due to the above loads or pressure is very small. Hence the slope in deflection is neglected.

3. $\sigma_{x}$ and $\sigma_{y}$ the normal stresses are assumed to be zero

4. The shear stress is also assumed to be zero at the middle surface of the plate.

5. The stress in $\mathrm{z}$ direction is transverse to the other direction is small and neglected as compared with other stress components [17],[18].

\section{RESULTS AND DISCUSSIONS}

The deflection and maximum stress is obtained from the flexural and dimensional parameters of simply supported head of the piston from analytical method using ANSYS software.

For the aluminum piston with

Thickness of head

Young's Modulus

$\mathrm{t}_{\mathrm{h}}=12 \mathrm{~mm}$

Pressure Applied

$\mathrm{E}=71000 \mathrm{MPa}$

Radius of the head

$\mathrm{q}=8 \mathrm{MPa}$

$\mathrm{a}=40 \mathrm{~mm}$

Then the corresponding

Flexural rigidity

$\mathrm{D}=11235164$

The following Table III shows the Comparison of the deflection and stress obtained from Analytical Method and ANSYS

Table 3: Comparison of the deflection and stress

\begin{tabular}{|l|c|c|}
\hline & ANALYTICAL & ANSYS \\
\hline Deflection $\boldsymbol{\omega}_{\max }$ & $0.0762 \mathrm{~mm}$ & $0.0708 \mathrm{~mm}$ \\
\hline Maximum stress $\left(\sigma_{r}\right)_{\max }$ & $97 \mathrm{MPa}$ & $91.77 \mathrm{MPa}$ \\
\hline
\end{tabular}

The corresponding deflection occurs at centre of the piston head is shown in the following Figure 1

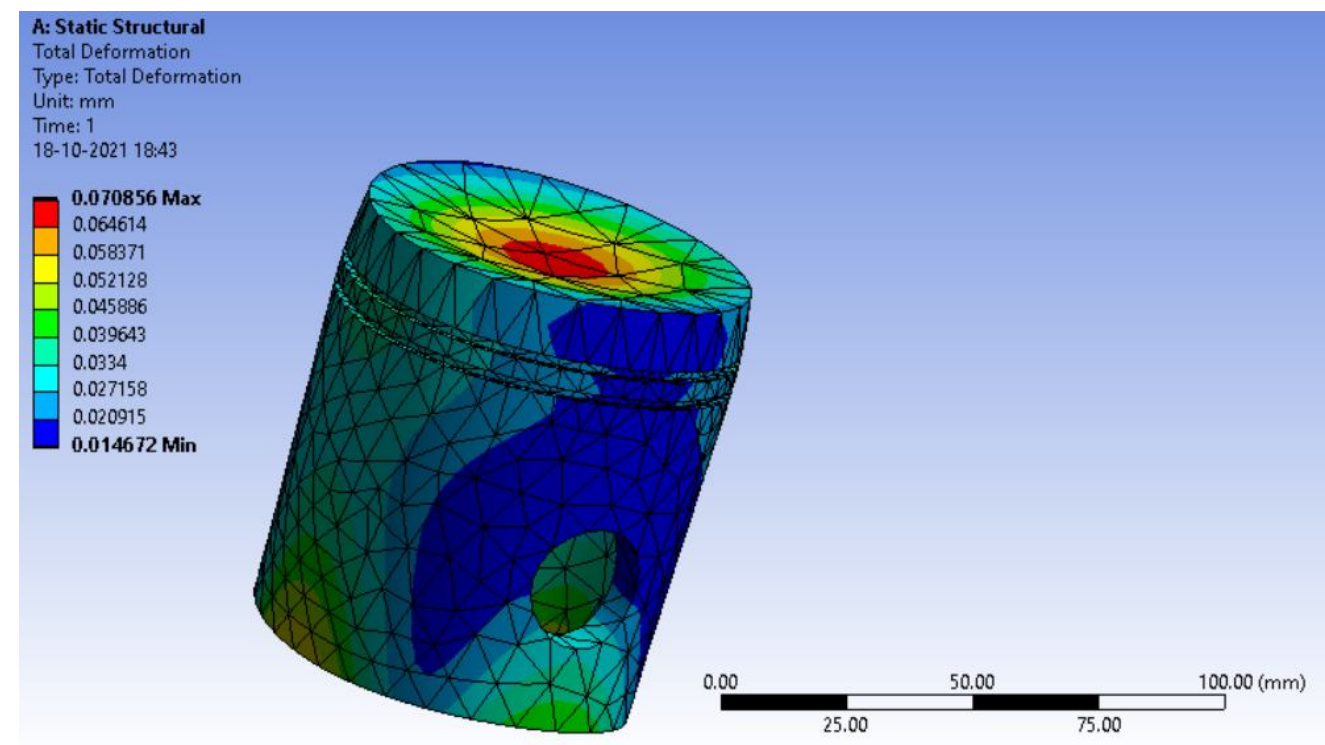

Figure 1: Deflection in Piston Head 
The equivalent von-Mise stress taking place in the piston and is shown in below Figure 2

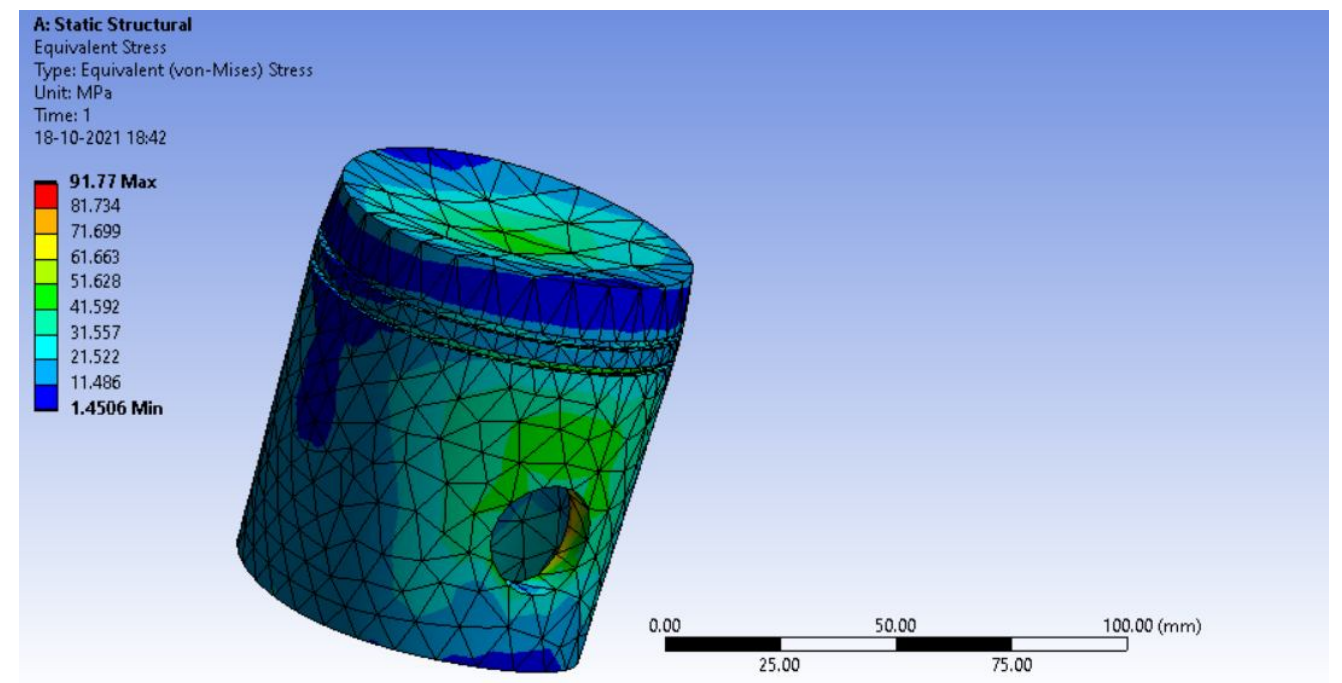

Figure 2: Equivalent von-Mises Stress

\section{DISCUSSIONS}

In this structural analysis the deflection and stress equations of simply supported circular plate were used for analytical solution. Since the head of the piston is in the circular shape. In this case it is necessary to determine the deflection occurs and stresses induced in the head of the piston. The simply supports were taken in the gudgeon hole where the gudgeon pin reacts the thermal loads applied on the top of the piston. The distance between the supports at the point and loads applied does not matter since the deflection due to the axial load is negligible. The same has been analyzed using ANSYS. The results were almost all same.

\section{CONCLUSION}

In the investigation on the structural analysis of the flat head piston, the top of the component is having circular shape. The mathematical modeling of the circular plate theory for deflection and stress adopted to calculate the same in case flat head piston. The same has been analyzed using ANSYS. The results of the analytical method compared with the same that of ANSYS gave for deflection and stress were $5.4 \%$ and 5.3\% respectively. Hence it can be concluded that the mathematical modeling of the circular plate theory can be adopted for determining the deflection and stress.

\section{REFERENCES}

[1] Charles J. Mueller, William J. Cannella, and Gautam T. Kalghatgi. Fuels for Engines and the Impact of Fuel Composition on Engine Performance. Encyclopedia of Automotive Engineering: 1-42. doi: 10.1002/9781118354179, 2014
[2] M. Shariyat, J. Fathi Sola, and S.A. Jazayeri.. Experimentally Validated Combustion and Piston Fatigue Life Evaluation Procedures for the Bi-Fuel Engines, Using an Integral-Type Fatigue Criterion. Latin American Journal of Solids and Structures 13: 10301053. 2016

[3] Singh, A., Deb, A., Mensi, A., and Gunti, R.. A Unified CAE Framework for Assessing an IC Engine Design. SAE Technical Paper 2015-01-1664. doi:10.4271/201501-1664. 2015

[4] H. M. I. Al-Zuhairi and I. Alshalal, Enhancement of Mechanical Properties of Aluminum Piston Alloy Using $\mathbf{A l}_{2} \mathbf{O}$ Material, 6th International Engineering Conference "Sustainable Technology and Development" (IEC), 2020, pp. 196-200, doi: 10.1109/IEC49899.2020.9122921. 2020

[5] Maaz Akhtar, Sayyad Zahid Qamar, Muzamil Muhammad \& Ali Nadeem, Optimum heat treatment of aluminum alloy used in manufacturing of automotive piston components, Materials and Manufacturing Processes, 33:16, 18741880, DOI: 10.1080/10426914.2018.1512128, 2018

[6] Edtmayer, J., Lösch, S., Hick, H. et al. Comparative study on the friction behaviour of piston/bore interface technologies. Automot. Engine Technol. 4, 101-109 (2019). https://doi.org/10.1007/s41104-019-00045-x, 2019 
[7] I.J.Isaac Premkumar, P.Ganeshan, et al., An investigation on Piston structural analysis related with experimental cylinder pressures using different biodiesel blend ratios Material Today Proceedings, Volume 22, Part 4, Pages 2255-2265 https://doi.org/10.1016/j.matpr.2020.03.346, 2020

[8] CM Peng, GD Zhang, JF Gong, et al., Research On Thermal Load Characteristics Of Piston Based On Fluid-Structure Coupled Heat Transfer. IOP Conf. Series: Materials Science and Engineering, 423, 012138 doi:10.1088/1757-899X/423/1/012138, 2018.

[9] Mark P. Gorton.. Carbon-Carbon Piston Development. National Aeronautics and Space Administration Contractor Report 4595: 1-14., 1994

[10] G. Rohini Devi and K. Rama Rao. Carbon-Carbon Composites -An Overview. Defense Science Journal 43 (4): 369-383, 1993

[11] Cambridge University Engineering Department. 2003. Materials Data Book. Edition: Cambridge University Engineering Department, 2003

[12] M. Gamal Fouad, Nouby M. Ghazaly, Ali M. Abd-ElTawwab, and k. A. Abd El-Gwwad. Finite Element Thermal Analysis of A Ceramic Coated Si Engine Piston Considering Coating Thickness. American Journal of Engineering Research 6 (2): 109-113, 2017.

[13] C Joel, S Anand, S Padmanabhan, and Yadav S Prasanna Raj. Thermal Analysis of Carbon-Carbon Piston for Commercial vehicle diesel engine using CAE Tool. International Journal of Ambient Energy: doi: 10.1080/01430750.2018.1525594, 2018.

[14] Grzegorz Koszałka, and Mirosław Guzik. Mathematical Model of Piston Ring Sealing in Combustion Engine. Polish Maritime Research 4 (84): 66-78 10.2478/pomr2014-0043. 2014.

[15] Grzegorz Koszalka and Andrzej Suchecki. Analysis of Design Parameters of Pistons and Piston Rings of a Combustion Engine. MATEC Web of Conferences 118: 1-5. doi:10.1051/matecconf/201711800013, 2017.

[16] R.S.Khurmi, J.K.Gupta, A Text Book of Machine Design ; Eurasia Publishing House (Pvt.) Ltd, pp. 1132-1140.. 2005

[17] S. Timoshenko and S. Woinowsky-Krieger, Theory of plates and shells, 2nd Edition, Tata McGraw Hill Education Private Limited. 2010. Pp. 56-57

[18] Xiao-Ting He, Qiang Chen, Jun-Yi Sun, Zhou-Lian Zheng and Shan-Lin Chen, Application of the Kirchhoff Hypothesis to Bending Thin Plates with Different
Moduli in Tension and Compression, Journal Of Mechanics Of Materials, Vol 5 No.5, 2010 